\title{
Usefulness of Implementing Comprehensive Pharmaceutical Care for Metastatic Renal Cell Carcinoma Outpatients Treated with Pazopanib
}

\author{
MAKI TODO ${ }^{1}$, SUGURU SHIROTAKE ${ }^{2}$, KOSHIRO NISHIMOTO ${ }^{2}$, YOTA YASUMIZU ${ }^{2}$, GOU KANEKO ${ }^{2}$, \\ HIDEYUKI KONDO ${ }^{2}$, TAKASHI OKABE ${ }^{2}$, HIDEKI MAKABE ${ }^{1}$ and MASAFUMI OYAMA ${ }^{2}$ \\ ${ }^{1}$ Department of Pharmacy, International Medical Center, Saitama Medical University, Saitama, Japan; \\ ${ }^{2}$ Department of Uro-Oncology, International Medical Center, Saitama Medical University, Saitama, Japan
}

\begin{abstract}
Background: Pazopanib is an effective treatment option for renal cell carcinoma (RCC). However, the therapy is often limited by the appearance of adverse events (AEs), including nausea/vomiting, hepatic impairment, hand-foot syndrome, diarrhea, hypertension and oral mucositis. Early management of AEs is, therefore, extremely important in order to maximize treatment outcomes. Patients and Methods: This non-randomized controlled before-and-after study was carried out to evaluate the effectiveness of our comprehensive pharmaceutical interventions in 37 outpatients receiving pazopanib for RCC (experimental group). Data were compared with those obtained from 13 patients before the start of pharmaceutical intervention (control group). Results: The incidence rates of grade 2 or more nausea and anorexia were significantly lower in the experimental, than in the control group (3\% versus $38 \%$ for nausea, respectively, $p=0.003 ; 8 \%$ versus $46 \%$ for anorexia, respectively, $p=0.005)$. Importantly, non-adherence based on patient self-assessment was not observed with intervention (0\% versus 38\%, $p<0.001)$. Consequently, the median total dose of pazopanib was increased by the intervention $(72,600$ versus $18,200 \mathrm{mg}, \mathrm{p}=0.002)$. Moreover, the median time to treatment failure was significantly longer with intervention than before (10.2 versus 1.7 months, $H R=0.23,95 \% C I=0.110-0.499, p<0.001)$. These findings suggest that our interventions are highly effective for enhancing treatment outcomes.
\end{abstract}

Pazopanib is an effective treatment option for advanced renal cell carcinoma (RCC). However, the therapy is often limited

Correspondence to: Maki Todo, Department of Pharmacy International Medical Center, Saitama Medical University, 1397-1, Yamane, Hidaka, Saitama, 350-1298, Japan. Tel: +81 429844646, Fax: +81 429844168, e-mail: m_todo@saitama-med.ac.jp

Key Words: Pazopanib, adverse events, pharmaceutical care, renal cell carcinoma, metastasis. by the appearance of adverse events (AEs), including nausea/vomiting, hepatic impairment, hand-foot syndrome, diarrhea, hypertension and oral mucositis $(1,2)$. Early management of AEs is, thus, extremely important for obtaining maximum treatment outcomes.

Pazopanib has inhibitory actions on multiple kinases associated with growth factor receptors, such as plateletderived growth factor receptors $\alpha$ and $\beta$; vascular endothelial growth factor receptors 1,2 , and 3 ; and stem cell factor receptor (c-KIT) $(3,4)$. This drug was approved as a first-line tyrosine-kinase inhibitor-targeted therapy for metastatic RCC based on the findings obtained from phase III clinical trials indicating that the drug produced significantly longer progression-free survival with a trend toward better overall survival compared to placebo $(3,5)$. The COMPARZ trial was a phase III non-inferiority study comparing sunitinib with pazopanib in a first-line setting, in which pazopanib was found to be non-inferior to sunitinib with respect to progression-free survival [hazard ratio $(\mathrm{HR})=1.05,95 \%$ confidence interval $(\mathrm{CI})=0.90-1.22]$, meeting the predefined non-inferiority margin. The non-inferiority with respect to overall survival was similar (HR=0.91, 95\% CI=0.76-1.08) (1).

Despite the positive therapeutic profile of pazopanib, however, it is unfortunately often difficult for physicians to secure sufficient time for the management of adverse reactions to the drug because of the limited time for consultations with outpatients. Therefore, it is extremely important for other healthcare professionals, including pharmacists, to provide comprehensive supportive care for the management of AEs in patients receiving pazopanib.

At our outpatient cancer chemotherapy clinic, an oncology medical team consisting of physicians, nursing staff and pharmacists, including an oncology pharmacist, provide pharmaceutical care for preventing or curing AEs associated with cancer chemotherapy. We, therefore, conducted a prospective cohort study to evaluate the effects of such pharmaceutical interventions on the incidence of AEs and the duration of therapy in outpatients who received pazopanib for RCC. 


\section{Patients and Methods}

Patients and treatments. This was a non-randomized controlled before-and-after study. Pharmaceutical interventions were commenced on September 2014. The subjects were 37 outpatients who received pazopanib at our outpatient cancer chemotherapy clinic during the period between September 2014 and November 2016 (experimental group). Their data were compared with those obtained from 13 outpatients who received pazopanib without pharmaceutical intervention during the period between May 2014 and September 2014 (control group). Within this period, all outpatients were included. No patients were excluded. Pazopanib was initially administered orally once daily. In cases of the appearance of moderate to severe AEs to the drug, the dose and administration of pazopanib were modified according to the manufacturer's instructions for appropriate use of the drug. Therapy was continued until disease progression or the occurrence of intolerable AEs.

Statement of ethics. All clinical investigations were approved by the Clinical Ethics Committee at the International Medical Center, Saitama Medical University (approval no. 15-240).

Establishment of a hotline between patients and healthcare professionals, particularly the attending pharmacist. It should be noted that a dedicated hotline was established such that patients and the attending pharmacist could talk and communicate directly with each other. This system allowed us to call patients at home and monitor pazopanib AEs and adherence, and also enabled patients to call the attending pharmacist and ask medication-related questions from the comfort of their homes.

Pharmaceutical interventions. Pharmacists, including an oncology pharmacist, carried out interviews with the patient in a separate room any time between their arrival at the hospital and their examination after blood collection. All data obtained by the pharmacist on symptoms, adherence to drugs, and presence or absence of AEs were entered into their electronic medical records, to facilitate information sharing among the different healthcare professions. Moreover, pharmacists continuously provided supportive care and drug administration guidance to the patients and confirmed their awareness and knowledge regarding AEs, symptom management and drug adherence. Pharmacists offered suggestions to the physician regarding treatment for the relief of AEs if the patient complained of moderate to severe AEs, including tyrosine kinase inhibitor-induced nausea and vomiting (TINV), oral mucositis, diarrhea, hypertension, or hand-foot syndrome. Antiemetic drugs, including metoclopramide, were not usually prescribed as premedication but were used for the rescue of TINV or as premedication in patients who were known to have experienced TINV with a previous administration. Pazopanib fits into the category of agents of low emetogenic potential risk group in the guideline for prevention of therapy-induced nausea and vomiting (6). In this guideline, a single antiemetic agent, such as dexamethasone, a 5-hydroxytryptamine-3 receptor antagonist or a dopamine receptor antagonist, such as metoclopramide, may be considered for prophylaxis in patients receiving therapy of low emetic risk. Furthermore, dose reduction was suggested to the attending doctor for patients who experienced serious TINV with previous administration. For the prevention of oral mucositis, preventive measures, including regular gargling with saline containing azulene sodium sulfonate, were suggested to the attending doctor (7). When the signs of oral mucositis progressed to grade $>1$, gargles containing hangeshashinto $(8,9)$ were recommended.

For preventing diarrhea, patients were instructed to take a lactobacillus preparation (10) regularly from the start of tyrosinekinase inhibitor therapy. Loperamide (11) was also prescribed for use when required. Skin moisturizers (in the form of an ointment containing a heparin-like substance) were prescribed for prevention of hand-foot syndrome. To prevent hypertension, patients were instructed to measure and record their blood pressure twice (morning and evening) daily. Antihypertensive drugs, such as angiotensin II receptor blockers and calcium channel blockers or their combination were used when moderate to severe hypertension occurred following pazopanib treatment $(7,12-15)$. Furthermore polaprezinc was suggested to the attending doctor for patients who experienced taste disturbances. It has been reported that polaprezinc, a zinc-carnosine chelate compound with anti-ulcer action (16), is effective in ameliorating taste disturbances (17).

When a new drug was prescribed, the pharmacist was in charge of providing instructions to the patient regarding usage of the drug. The above-mentioned pharmaceutical care was provided to ensure that patients were free of discomfort from AEs and were taking a proactive stance regarding therapy.

Evaluation of drug adherence. Adherence to therapy for pazopanib and other drugs was evaluated from the patient's daybook at every patient visit. The daybook, which is provided by the manufacturer of pazopanib for patients with RCC, was provided by the pharmacist on the first visit so that patients could record the drugs taken and their AE symptoms on a daily basis.

Outcome evaluation. The study compared the incidence of AEs and the reasons for discontinuation of drug intake, total doses over the administration period, and the time to treatment failure (TTF) before and after implementation of pharmaceutical interventions. The time point for beginning of TTF was defined as the start date of treatment with pazopanib, and that for ending of TTF as the end date of treatment with pazopanib. AEs were assessed according to the National Cancer Institute Common Terminology Criteria for Adverse Events, version 4.0.(18).

Statistical analyses. Data were analyzed using the Statistics Program for Social Science for Windows (SPSS-II version 11; SPSS, Chicago, IL, USA) and statistically compared before and after implementation of pharmaceutical interventions. The $t$-test was used for parametric analysis, while the Mann-Whitney $U$-test or Fisher's exact probability test was used for non-parametric data analysis. TTF was calculated by the Kaplan-Meier method (19) and a beforeand-after implementation of pharmaceutical care comparison was performed by the Mantel-Cox log-rank test. A $p$-value of less than 0.05 was regarded as statistically significant.

\section{Results}

Patient demographics. The characteristics of the participants are shown in Table I. No significant differences were observed before and after pharmaceutical interventions, except for the item of bone metastases, which was significantly less frequent in the experimental group than in the control group ( $19 \%$ versus $62 \%, p=0.01$ ). 
Table I. Characteristics of patients.

\begin{tabular}{|c|c|c|c|}
\hline \multirow[b]{2}{*}{ Characteristic } & \multicolumn{2}{|c|}{ Intervention } & \multirow[b]{2}{*}{$p$-Value } \\
\hline & Without $(n=13)$ & With $(n=37)$ & \\
\hline \multicolumn{4}{|l|}{ Age, years } \\
\hline Median (range) & $66.0(43-80)$ & $67.0(46-80)$ & $0.499^{\mathrm{a}}$ \\
\hline \multicolumn{4}{|l|}{ Gender, $\mathrm{n}(\%)$} \\
\hline Male/female & $9(69 \%) / 4(31 \%)$ & $25(68 \%) / 12(32 \%)$ & $>0.99^{b}$ \\
\hline \multicolumn{4}{|l|}{ ECOG PS, n (\%) } \\
\hline $0 / 1 / 2 / 3$ & $5 / 5 / 2 / 1(39 \% / 39 \% / 15 \% / 8 \%)$ & $14 / 18 / 4 / 1(38 \% / 49 \% / 11 \% / 3 \%)$ & $0.746^{\mathrm{a}}$ \\
\hline \multicolumn{4}{|l|}{ MSKCC risk group, $\mathrm{n}(\%)$} \\
\hline Favorable/intermediate/poor & $2 / 7 / 4(15 \% / 54 \% / 31 \%)$ & $3 / 27 / 7(8 \% / 73 \% / 19 \%)$ & $0.757^{\mathrm{a}}$ \\
\hline \multicolumn{4}{|l|}{ Histological subtype, n (\%) } \\
\hline Clear cell/non-clear cell & $9 / 4(69 \% / 31 \%)$ & $31 / 6(84 \% / 16 \%)$ & $0.420^{\mathrm{b}}$ \\
\hline \multicolumn{4}{|l|}{ Site of metastasis, n (\%) } \\
\hline Lung & $11(85 \%)$ & $26(70 \%)$ & $0.469^{b}$ \\
\hline Lymph nodes & $5(38 \%)$ & $13(35 \%)$ & $>0.99^{\mathrm{b}}$ \\
\hline Liver & $4(31 \%)$ & $8(22 \%)$ & $0.707^{b}$ \\
\hline Bone & $8(62 \%)$ & $7(19 \%)$ & $0.010^{\mathrm{b}}$ \\
\hline Brain & $0(0 \%)$ & $3(8 \%)$ & $0.558^{\mathrm{b}}$ \\
\hline \multicolumn{4}{|l|}{ Therapy lines, $\mathrm{n}$} \\
\hline Mean (range) & $2.46(1-\geq 4)$ & $2.05(1-\geq 4)$ & $0.416^{\mathrm{a}}$ \\
\hline $1 / 2 / 3 / \geq 4, \mathrm{n}(\%)$ & $6 / 0 / 2 / 5$ & $19 / 5 / 5 / 8$ & \\
\hline & $(46 \% / 0 \% / 15 \% / 38 \%)$ & $(51 \% / 14 \% / 14 \% / 22 \%)$ & \\
\hline \multicolumn{4}{|c|}{ Previous radical nephrectomy, n (\%) } \\
\hline Yes & $9 / 4(69 \%)$ & $25(68 \%)$ & $>0.99^{b}$ \\
\hline \multicolumn{4}{|l|}{ Initial dose $\mathrm{mg}$, } \\
\hline Mean (IQR) & $615(400-800)$ & $551(400-600)$ & $0.283^{\mathrm{a}}$ \\
\hline $800 / 600 / 400 / 200$ & $5 / 4 / 4 / 0$ & $9 / 12 / 14 / 2$ & \\
\hline & $(38 \% / 31 \% / 31 \% / 0 \%)$ & $(24 \% / 32 \% / 38 \% / 5 \%)$ & \\
\hline \multicolumn{4}{|l|}{ Hemodialysis patients, $\mathrm{n}(\%)$} \\
\hline Yes & $0(0 \%)$ & $4(11 \%)$ & $0.561^{\mathrm{b}}$ \\
\hline
\end{tabular}

ECOG PS: Eastern Cooperative Oncology Group performance status; MSKCC: Memorial Sloan Kettering Cancer Center; IQR: interquartile range.

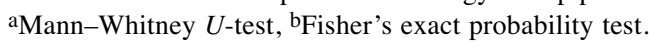

Incidence of grade 2 or more AEs associated with pazopanib. The incidence rates of grade 2 or more AEs are listed in Table II. The most frequent AE that appeared before pharmaceutical intervention was hypertension $(77 \%)$, followed by anorexia $(46 \%)$, nausea $(38 \%)$ and proteinuria $(38 \%)$. Implementation of the pharmaceutical intervention significantly reduced the incidence of both nausea ( $3 \%$ versus $38 \%, p=0.003$ ) and anorexia ( $8 \%$ versus $46 \%, p=0.005$ ) without significant influence on the incidence of other AEs.

Causes of treatment discontinuation. It is noteworthy that no reduction in adherence based on patient self-assessment was observed after pharmaceutical intervention, while nonadherence occurred in five out of 13 patients $(38 \%)$ of the control group $(p<0.001)$, as shown in Table III. Discontinuation due to the occurrence of nausea was also not observed after intervention, although it was seen in 4 of 13 patients $(31 \%)$ control group $(p=0.003)$.
Total amount of pazopanib and TTF. As shown in Table IV, the median total amount of pazopanib over the administration period was significantly higher for the experimental group [72,600 versus 18,200 mg, $p<0.005]$.

As shown in Table IV and Figure 1, the median TTF was significantly longer for the experimental group [10.2 $(95 \%$ $\mathrm{CI}=2.4-25.2)$ versus $1.7(95 \% \mathrm{CI}=0.9-2.2)$ months; $\mathrm{HR}=0.23$ (95\% CI=0.110-0.499) $p<0.001$, Mantel-Cox log-rank test].

\section{Discussion}

In the present study, patients receiving pazopanib experienced a number of AEs, including nausea/vomiting, hepatic impairment, hand-foot syndrome, diarrhea, hypertension and oral mucositis, which might lead to impairment of quality of life and a reduction in adherence to pharmacotherapy. Therefore, comprehensive pharmaceutical care for prevention of severe AEs should be provided to patients receiving 
Table II. Comparison of the incidence of grade 2 or more adverse events (AEs) associated with pazopanib without and with pharmaceutical intervention

\begin{tabular}{lccc}
\hline & \multicolumn{2}{c}{ Intervention } \\
\cline { 2 - 3 } Toxicity & Without (n=13) & With (n=37) & $p$-Value \\
\hline Non-hematological & & & \\
Nausea & $5(38)$ & $1(3)$ & $\mathbf{0 . 0 0 3}$ \\
Anorexia & $6(46)$ & $3(8)$ & $\mathbf{0 . 0 0 5}$ \\
Hand-foot skin reaction & $1(8)$ & $6(16)$ & 0.660 \\
Hypertension & $10(77)$ & $31(84)$ & 0.679 \\
Rash & $0(0)$ & $1(3)$ & $>0.99$ \\
Diarrhea & $0(0)$ & $6(16)$ & 0.319 \\
Fatigue & $4(31)$ & $6(16)$ & 0.420 \\
Dysgeusia & $3(23)$ & $10(27)$ & $>0.99$ \\
Protein urea & $5(38)$ & $14(38)$ & $>0.99$ \\
Oral mucositis & $1(8)$ & $2(5)$ & $>0.99$ \\
AST increased & $2(15)$ & $5(14)$ & $>0.99$ \\
ALT increased & $2(15)$ & $6(16)$ & $>0.99$ \\
Blood bilirubin increased & $2(15)$ & $2(5)$ & 0.275 \\
Hypothyroidism & $3(23)$ & $12(32)$ & 0.728 \\
Hematological & & & \\
Thrombocytopenia & $1(8)$ & $4(11)$ & $>0.99$ \\
Anemia & $4(31)$ & $3(8)$ & 0.065 \\
Neutropenia & $0(0)$ & $1(3)$ & $>0.99$ \\
\hline
\end{tabular}

AEs were graded according to the National Cancer Institute Common Terminology Criteria for Adverse events v4.0 (18). Data were statistically compared by the Fisher's exact probability test. Significant differences are shown in bold.

pazopanib. In terms of the incidence of grade 2 or more AEs, the incidence rates of nausea and anorexia were significantly reduced after the pharmaceutical intervention as compared with the control group (from $38 \%$ to $3 \%$ for nausea and from $46 \%$ to $8 \%$ for anorexia). In particular, two out of 13 patients $(15 \%)$ required emergency hospitalization due to the appearance of grade 3 nausea in the control group, whereas no cases of emergency admission were observed after intervention. In the present study, the incidence rates of both nausea and anorexia before intervention were much higher than those reported by Escudier et al., who showed incidence rates of $8 \%$ for nausea and $4 \%$ for anorexia (2). This may be due to the lack of appropriate use of antiemetic medication in the control group in the present study. One possible reason for the remarkable decrease in grade 2 or more nausea and anorexia due to the intervention could be that antiemetic drugs, including metoclopramide, were not usually prescribed as premedication, but were used for the rescue of TINV [nausea (grade 1)] or as premedication in patients who had experienced TINV with a previous administration. Furthermore, dose reduction was prescribed in patients who experienced serious TINV following a previous administration. In the present study, it was found that taste
Table III. Causes of treatment discontinuation in patients receiving pazopanib.

\begin{tabular}{llll}
\hline Cause of treatment discontinuation & \multicolumn{2}{l}{ Intervention, $\mathrm{n}(\%)$} & $p$-Value \\
\cline { 2 - 3 } & $\begin{array}{c}\text { Without } \\
(\mathrm{n}=13)\end{array}$ & $\begin{array}{c}\text { With } \\
(\mathrm{n}=37)\end{array}$ & \\
\hline Patient self-assessment & $5(38)$ & $0(0)$ & $\mathbf{< 0 . 0 0 1}$ \\
Incidence of main AEs & $8(62)$ & $9(24)$ & $\mathbf{0 . 0 2 1}$ \\
Nausea & $4(31)$ & $0(0)$ & $\mathbf{0 . 0 0 3}$ \\
Protein urea & $2(15)$ & $4(11)$ & 0.643 \\
AST/ALT increase & $0(0)$ & $2(5)$ & $>0.99$ \\
Bilirubin increase & $0(0)$ & $1(3)$ & $>0.99$ \\
Fatigue & $0(0)$ & $1(3)$ & $>0.99$ \\
Neutropenia & $0(0)$ & $1(3)$ & $>0.99$ \\
Bleeding from the gastrointestinal tract & $1(8)$ & $0(0)$ & 0.260 \\
Chest pain, cardiac & $1(8)$ & $0(0)$ & 0.260 \\
Choice of best supportive care & $0(0)$ & $1(3)$ & $>0.99$ \\
Progressive disease & $5(38)$ & $14(38)$ & $>0.99$ \\
\hline
\end{tabular}

AEs: Adverse events; AST: aspartate aminotransferase increased; ALT: alanine aminotransferase increased. Data were statistically compared by Fisher's exact probability test. Significant differences are shown in bold.

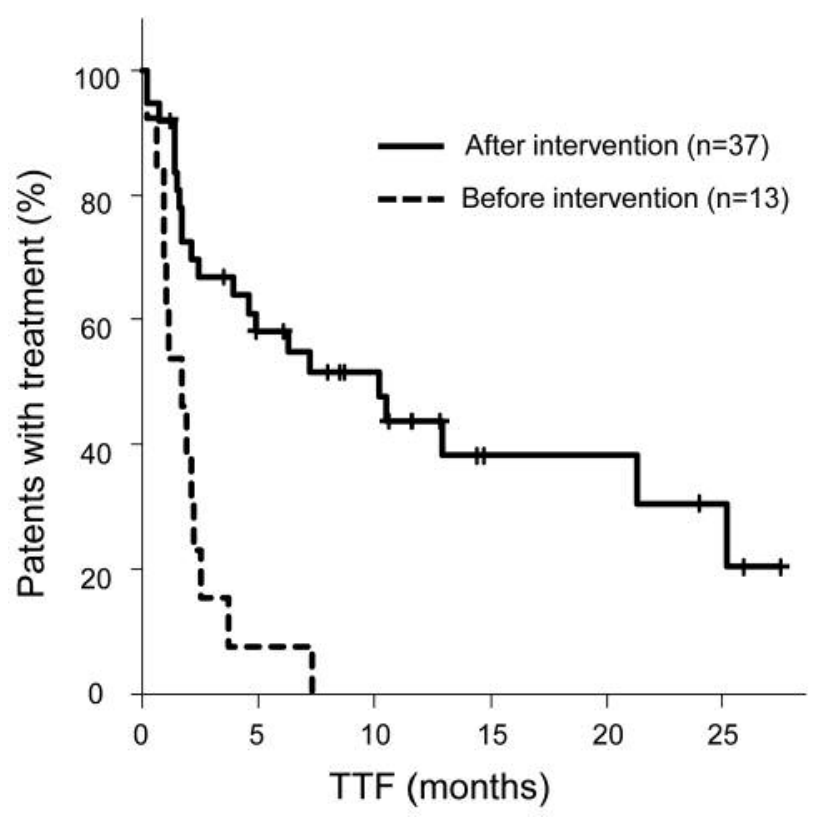

Figure 1. Kaplan-Meier plots for comparison of time to treatment failure (TTF) between the experimental group (after pharmaceutical intervention) and the control group (before intervention). Median TTF was 10.2 (95\% confidence interval=2.4-25.2) months versus 1.7 (95\% confidence interval $=0.9-2.2$ ) months, respectively (hazard ratio $=0.23,95 \%$ confidence intervaI=0.110-0.499, $p<0.001$ by Mantel-Cox log-rank test).

disturbances might contribute to the incidence of anorexia. Therefore, polaprezinc was administered to patients with taste disturbances in the present study. Indeed, polaprezinc was effective for the prevention of anorexia in such patients. 
Table IV. Clinical outcomes of patients receiving pazopanib with and without pharmaceutical intervention.

\begin{tabular}{|c|c|c|c|}
\hline & Without intervention & With intervention & $p$-Value \\
\hline Median total dose (range), mg & $18,200(2,800-50,800)$ & $72,600(2,800-660,400)$ & $0.002^{\mathrm{a}}$ \\
\hline Median time to treatment failure $(95 \% \mathrm{CI})$, months & $1.7(0.9-2.2)$ & $10.2(2.4-25.2)$ & \\
\hline Hazard ratio $(95 \% \mathrm{CI})$ & Referent & $0.23(0.110-0.499)$ & $<0.001^{\mathrm{b}}$ \\
\hline
\end{tabular}

CI: Confidence intervaI. Data were statistically compared by aMann-Whitney $U$-test or bMantelCox log-rank test.

In this study, the incidence rates of other AEs were not significantly different between the two groups. Among the various AEs induced by pazopanib treatment, some, including nausea, are preventable by medication, while others, such as bleeding and abnormal parameters indicating hepatic dysfunction, renal failure and proteinuria, are not easily controlled. Therefore, dose reduction based on the physical condition of patients and careful monitoring of such AEs are particularly important.

A number of oral chemotherapy drugs that inhibit the growth of cancer cells through inhibition of intracellular protein kinases have been developed in recent years, although most of them have a number of undesirable sideeffects that are different from those of conventional cytotoxic anticancer drugs. Several investigators have shown that the occurrence of AEs leads to poor medication adherence in patients receiving oral chemotherapeutic drugs, including pazopanib (20-23), indicating the importance of monitoring for AEs and provision of extensive pharmaceutical care in the maintenance of drug adherence. It has also been demonstrated that poor adherence to imatinib, an inhibitor of breakpoint cluster region/Abelson tyrosine kinase used for the therapy of chronic myeloid leukemia, results in worse treatment outcomes $(24,25)$.

In the present study, comprehensive pharmaceutical interventions enabled early detection and management of AEs which might lead to reduction in treatment interruption. More importantly, non-adherence based on the patient self-assessment was no longer observed after the pharmaceutical intervention, while it was observed in 5 of 13 patients $(38 \%)$ before the intervention. This may be due to the establishment of the telephone consultation hotline system between patients and the attending pharmacist. Patients often called the attending pharmacist to ask medication-related questions. As a consequence, the median TTF was significantly prolonged from 1.7 to 10.2 months $(\mathrm{HR}=0.23,95 \% \mathrm{CI}=0.110-0.499 p<0.001)$ and the total amount of pazopanib increased significantly ( $p=0.002$ ) from $18,200 \mathrm{mg}$ to $72,600 \mathrm{mg}$, indicating that the present pharmaceutical intervention yielded favorable clinical outcomes.

Several limitations to the present study must be considered. Firstly, this was a single-institutional, non- randomized before and after study. Secondly, the sample size was too small. Thirdly, study subjects were limited to patients with RCC who received pazopanib, and hence, its results cannot be generalized to other patient populations.

In summary, comprehensive pharmaceutical interventions, including patient education, establishment of a hotline and management of AEs, were provided to patients receiving pazopanib for RCC at our outpatient cancer chemotherapy clinic. Pharmacists consulted with patients before their examination by physicians to provide comprehensive pharmaceutical care. Moreover, a telephone consultation hotline was set up to facilitate communication between patients and the attending pharmacist. Consequently, nonadherence was no longer observed after implementation of the pharmaceutical interventions. Furthermore, the median TTF was significantly prolonged and the total amount of pazopanib administered was enhanced after intervention.

\section{Conclusion}

Our management strategy of pharmaceutical care appeared to contribute to the attainment of better clinical outcomes in RCC outpatients receiving pazopanib.

\section{Conflicts of Interest}

No Authors have any conflicts of interest to declare in regard to this study.

\section{Acknowledgements}

The Authors express their great thanks to Dr. Yoshinori Itoh, Department of Pharmacy, Gifu University Hospital, for his assistance instruction with this article.

\section{References}

1 Motzer RJ, Hutson TE, Cella D, Reeves J, Hawkins R, Guo J, Nathan P, Staehler M, de Souza P, Merchan JR, Boleti E, Fife $\mathrm{K}$, Jin J, Jones R, Uemura H, De Giorgi U, Harmenberg U, Wang J, Sternberg CN, Deen K, McCann L, Hackshaw MD, Crescenzo R, Pandite LN and Choueiri TK: Pazopanib versus sunitinib in metastatic renal-cell carcinoma. N Engl J Med 369: 722-731, 2013 
2 Escudier B, Porta C, Bono P, Powles T, Eisen T, Sternberg CN, Gschwend JE, De Giorgi U, Parikh O, Hawkins R, Sevin E, Négrier S, Khan S, Diaz J, Redhu S, Mehmud F and Cella D: Randomized, controlled, double-blind, cross-over trial assessing treatment preference for pazopanib versus sunitinib in patients with metastatic renal cell carcinoma. PISCES Study. J Clin Oncol 32: 1412-1418, 2014.

3 McCormack PL: Pazopanib: A review of its use in the management of advanced renal cell carcinoma. Drugs 74: 1111$1125,2014$.

4 Kumar R, Knick VB, Rudolph SK, Johnson JH, Crosby RM, Crouthamel MC, Hopper TM, Miller CG, Harrington LE, Onori JA, Mullin RJ, Gilmer TM, Truesdale AT, Epperly AH, Boloor A, Stafford JA, Luttrell DK and Cheung M: Pharmacokinetic-pharmacodynamic correlation from mouse to human with pazopanib, a multikinase angiogenesis inhibitor with potent antitumor and antiangiogenic activity. Mol Cancer Ther 6: 2012-2021, 2007.

5 Sternberg CN, Hawkins RE, Wagstaff J, Salman P, Mardiak J, Barrios CH, Zarba JJ, Gladkov OA, Lee E, Szczylik C, McCann L, Rubin SD, Chen M and Davis ID: A randomised, doubleblind phase III study of pazopanib in patients with advanced and/or metastatic renal cell carcinoma: Final overall survival results and safety update. Eur J Cancer 49: 1287-1296, 2013.

6 Roila F, Molassiotis A, Herrstedt J, Aapro M, Gralla RJ, Bruera E, Clark-Snow RA, Dupuis LL, Einhorn LH, Feyer P, Hesketh PJ, Jordan K, Olver I, Rapoport BL, Roscoe J, Ruhlmann CH, Walsh D, Warr D and van der Wetering M; participants of the MASCC/ESMO Consensus Conference Copenhagen 2015: 2016 MASCC and ESMO guideline update for the prevention of chemotherapy- and radiotherapy-induced nausea and vomiting and of nausea and vomiting in advanced cancer patients. Ann Oncol 27: v119-v133, 2016.

7 Arakawa-Todo M, Yoshizawa T, Zennami K, Nishikawa G, Kato Y, Kobayashi I, Kajikawa K, Yamada Y, Matsuura K, Tsukiyama I, Saito H, Hasegawa T, Nakamura K and Sumitomo M: Management of adverse events in patients with metastatic renal cell carcinoma treated with sunitinib and clinical outcomes. Anticancer Res 33: 5043-5050, 2013.

8 Kono T, Kaneko A, Matsumoto C, Miyagi C, Ohbuchi K, Mizuhara Y, Miyano K, and Uezono Y: Multitargeted effects of hangeshashinto for treatment of chemotherapy-induced oral mucositis on inducible prostaglandin E2 production in human oral keratinocytes. Integr Cancer Ther 13: 435-445, 2014.

9 Matsuda C, Munemoto Y, Mishima H, Nagata N, Oshiro M, Kataoka M, Sakamoto J, Aoyama T, Morita S and Kono T: Double-blind, placebo-controlled, randomized phase II study of TJ-14 (Hangeshashinto) for infusional fluorinated pyrimidinebased colorectal cancer chemotherapy-induced oral mucositis. Cancer Chemother Pharmacol 76: 97-103, 2015.

10 Bowen JM, Stringer AM, Gibson RJ, Yeoh AS, Hannam S and Keefe DM: VSL\#3 probiotic treatment reduces chemotherapyinduced diarrhea and weight loss. Cancer Biol Ther 6: 14491454, 2007.

11 Benson AB 3rd, Ajani JA, Catalano RB, Engelking C, Kornblau SM, Martenson JA Jr., McCallum R, Mitchell EP, O'Dorisio TM, Vokes EE and Wadler S: Recommended guidelines for the treatment of cancer treatment-induced diarrhea. J Clin Oncol 22: 2918-2926, 2004.

12 Keizman D, Huang P, Eisenberger MA, Pili R, Kim JJ, Antonarakis ES, Hammers $\mathrm{H}$ and Carducci MA: Angiotensin system inhibitors and outcome of treatment with sunitinib in patients with metastatic renal cell carcinoma: A retrospective examination. Eur J Cancer 47: 1955-1961, 2011.

13 Penttilä P, Rautiola J, Poussa T, Peltola K and Bono P: Angiotensin inhibitors as treatment of sunitinib/pazopanibinduced hypertension in metastatic renal cell carcinoma. Clin Genitourin Cancer 15: 384-390, 2017.

14 Sane DC, Anton L and Brosnihan KB: Angiogenic growth factors and hypertension. Angiogenesis 7: 193-201, 2004.

15 Izzedine H, Ederhy S, Goldwasser F, Soria JC, Milano G, Cohen A, Khayat D and Spano JP: Management of hypertension in angiogenesis. Ann Oncol 20: 807-815, 2009.

16 Dajani EZ and Klamut MJ: Novel therapeutic approaches to gastric and duodenal ulcers: an update. Expert Opin Investig Drugs 9: 1537-1544, 2000.

17 Watanabe T, Ishihara M, Matsuura K, Mizuta K and Itoh Y: Polaprezinc prevents oral mucositis associated with radiochemotherapy in patients with head and neck cancer. Int J Cancer 127: 1984-1990, 2010.

18 U.S. Department of Health and Human Services, National Institutes of Health National Cancer Institute. Common Terminology Criteria for Adverse Events (CTCAE) Version 4.0. (https://www.eortc.be/services/doc/ctc/), 2009.

19 Kaplan EL and Meier P: Nonparametric estimation from incomplete observations. J Am Stat Assoc 53: 29-41, 1958.

20 Ribed A, Romero-Jiménez RM, Escudero-Vilaplana V, IglesiasPeinado I, Herranz-Alonso A, Codina C and Sanjurjo-Sáez M: Pharmaceutical care program for onco-hematologic outpatients: safety, efficiency and patient satisfaction. Int J Clin Pharm 38: 280-288, 2016.

21 Todo M, Ueda S, Osaki A, Sugitani I, Takahashi T, Takahashi M, Makabe H, Saeki T and Itoh Y: Improvement of treatment outcomes after implementation of comprehensive pharmaceutical care in breast cancer patients receiving everolimus and exemestane. Die Pharmazie 73: 110-114, 2018.

22 Hackshaw MD, Nagar SP, Parks DC and Miller LA: Persistence and compliance with pazopanib in patients with advanced renal cell carcinoma within a U.S. administrative claims database. J Manag Care Spec Pharm 20: 603-610, 2014.

23 Deutsch S, Koerner P, Miller RT, Craft Z and Fancher K: Utilization patterns for oral oncology medications in a specialty pharmacy cycle management program. J Oncol Pharm Pract 22: 68-75, 2016.

24 Marin D, Bazeos A, Mahon FX, Eliasson L, Milojkovic D, Bua M, Apperley JF, Szydlo R, Desai R, Kozlowski K, Paliompeis C, Latham V, Foroni L, Molimard M, Reid A, Rezvani K, de Lavallade H, Guallar C, Goldman J and Khorashad JS: Adherence is the critical factor for achieving molecular responses in patients with chronic myeloid leukemia who achieve complete cytogenetic responses on imatinib. J Clin Oncol 28: 2381-2388, 2010.

25 Ibrahim AR, Eliasson L, Apperley JF, Milojkovic D, Bua M, Szydlo R, Mahon FX, Kozlowski K, Paliompeis C, Foroni L, Khorashad JS, Bazeos A, Molimard M, Reid A, Rezvani K, Gerrard G, Goldman J and Marin D: Poor adherence is the main reason for loss of CCyR and imatinib failure for chronic myeloid leukemia patients on long-term therapy. Blood 117: 3733-3736, 2011.

Received December 15, 2018

Revised January 11, 2019

Accepted January 16, 2019 